\title{
Association of Vitamin $D_{3}$ levels with Glycemic Control in Type 2 Diabetes Subjects from Gujarati population-India
}

\author{
Avisek Majumder ${ }^{1 *}$, Bhavik Doshi ${ }^{1}$, Frenny Sheth ${ }^{1}$, Manan Patel ${ }^{1}$, Navneet Shah ${ }^{2}$, Thakor Premal ${ }^{3}$, Rama Vaidya ${ }^{4}$, \\ Jayesh Sheth ${ }^{1}$ \\ From International Conference on Human Genetics and 39th Annual Meeting of the Indian Society of \\ Human Genetics (ISHG) \\ Ahmadabad, India. 23-25 January 2013
}

\section{Background}

Considering the active role of Vitamin $\mathrm{D}_{3}$ in the functional regulation of pancreatic $\beta$-cells, present study was carried out to know the occurrence of Vitamin $\mathrm{D}_{3}$ deficiency in Type 2 diabetic [T2D] and non-diabetic subjects and demonstrate its influence on glycemic control.

\section{Materials and Methods}

This prospective study comprises of 508 individuals (including 210 T2D \& 298 controls). All subjects were categorized into 3 groups according to Vitamin $\mathrm{D}_{3}$ levels. Group-I: included 171 individuals (61 T2D out of 171) with normal Vitamin $D_{3}$ concentration ( $\geq 25 \mathrm{nmol} / \mathrm{l}$ ), group-II: included 264 subjects (118 T2D out of 264)with mild to moderately Vitamin $\mathrm{D}_{3}$ deficiency $(15-24.9 \mathrm{nmol} / \mathrm{l})$ and group-III included 73 subjects (31 T2D out of 73) having severe Vitamin $\mathrm{D}_{3}$ deficiency $(\leq 14.9 \mathrm{nmol} / \mathrm{l})$. Vitamin $\mathrm{D}_{3}$ and glycosylated hemoglobin [HbA1C] level was analyzed for all the subjects.

\section{Results}

Overall 66.34\% subjects (both T2D \& Controls) were found to have Vitamin $\mathrm{D}_{3}$ deficiency. This was more common in T2D patients $(71 \%)\left(\right.$ mean \pm SD Vitamin $\mathrm{D}_{3}$ level was $17.77 \pm 7.19 \mathrm{nmol} / \mathrm{L})$ as compared to controls $(63 \%)$ $($ mean \pm SD Vitamin D3 level was $24.38 \pm 9.30 \mathrm{nmol} / \mathrm{L})$ $(\mathrm{p}<0.05)$.Female subjects were more prone for Vitamin $\mathrm{D}_{3}$ deficiency as compared to male $(71.09 \%$ vs $61.09 \%$, $\mathrm{p}<0.03)$ subjects. Moreover, a gradual increase in mean
HbA1C level was observed as Vitamin $\mathrm{D}_{3}$ level when reduced from its normal level in T2D subjects (7.95$9.08 \%$ in group-I through group-III) [ $\beta \mathrm{HbA} 1 \mathrm{C}$, Vit. D3= $\left.-0.07, \mathrm{r}=-0.28, \mathrm{p}<2.73 \times 10^{-5}\right]$. No such changes in mean $\mathrm{HbA} 1 \mathrm{C}$ level were observed in controls.

\section{Conclusion}

Present study demonstrates the high prevalence (66.34\%) of Vitamin $\mathrm{D}_{3}$ deficiency in Gujarati population from India, more so for subjects with T2D. It is likely that Vitamin $\mathrm{D}_{3}$ has a role in regulating insulin sensitization; resulting in poor glycemic control in subjects with low Vitamin $D_{3}$ levels. This study also indicates that females are likely to be at a higher risk for Vitamin $\mathrm{D}_{3}$ deficiency compared to male in $\mathrm{T} 2 \mathrm{D}$ and control subjects.

\section{Authors' details}

'FRIGE's Institute of Human Genetics, FRIGE House, Jodhpur Gam Road, Satellite, Ahmedabad-380015, India. ${ }^{2}$ Department of Diabetes and Endocrinology; Sterling Hospital, Ahmedabad- 380052, India. ${ }^{3}$ Gujarat Diabetic Association, Ahmedabad-380007, India. ${ }^{4}$ Kasturba Health Society, Medical Research Centre, Mumbai-400056, India.

Published: 21 January 2014

doi:10.1186/1755-8166-7-S1-P36

Cite this article as: Majumder et al: Association of Vitamin $D_{3}$ levels with Glycemic Control in Type 2 Diabetes Subjects from Gujarati population-India. Molecular Cytogenetics 2014 7(Suppl 1):P36.

\footnotetext{
*Correspondence: avi.biocv@gmail.com

'FRIGE's Institute of Human Genetics, FRIGE House, Jodhpur Gam Road,

Satellite, Ahmedabad-380015, India

Full list of author information is available at the end of the article
} 